\title{
Aboriginal Dietary Culture and Community Tourism Development-A Case of the Amis Matai' an Tribe, Taiwan
}

\author{
Yi-Su Chen
}

\begin{abstract}
In the face of severe challenge in the globalization era, how to conserve aboriginal culture as well as build aboriginal competitiveness in the free market becomes an important issue in enriching plural ethnic culture. Food is usually regarded as the fundamental element of cultural and social interaction, diet carries symbolic information of cultural tradition in the society. On the other hand, creativity living industry is the unique type of Cultural and Creative Industries in Taiwan, and it is full of experimental vitality. However, how to develop Amis dietary culture into promising creativity living industry is still rare in the field of academic research. This research is intended to fill in these academic blanks. Therefore, in the present study, the Matai'an Tribe in Guangfu, Hualien County, Taiwan served as a research base. This project will conduct a field survey and interview with local persons and professionals in Hualien to collect basic data and information. Social network analysis (SNA) is applied to analyze the mechanism which can effectively transform the Amis's dietary culture into creativity living industry. Finally, this research found that dietary culture offers an alternative means of local and regional development, with the potential to strengthen identity, enhance appreciation of the environment, encouraged the regeneration of local heritage and the economy.
\end{abstract}

Index Terms-Amis dietary culture, creativity living industry, food tourism, SNA (social network Analysis).

\section{INTRODUCTION}

In response to globalization, Taiwan's local culture and local industries caused by the impact, the government actively promoting the development of local cultural industries, this opportunity makes located in "vulnerable" or "border" of the community through the development of local cultural industries, as the resistance mainstream culture of the local forces. Besides, since the 1980s, with the deterritorialization and time-space compression that comes with advanced modernization, the social, political and aesthetic properties potentially associated with cuisine have come to be immensely significant in modem societies. Against this backdrop, food has gradually become a central focus of socio-cultural forces and gained a key position that reflects socio-cultural power relations [1]. The food consumption plays an important role in the process of tourism experiences. It can be an important purpose of the tour. Destinations with best chances for developing a gastronomy tourism product are

Manuscript received August 15, 2017; October 12, 2017.

Yi-Su Chen is with Ph. D Program in Civil and Hydraulic Engineering, Feng Chia University, Taichung, Taiwan (e-mail morning7151@ hotmail.com). those destinations that already have the advantageous "ingredients" to support a gastronomy tourism strategy. Such resources include unique and/or multi-ethnic cuisine, creative chefs, unique marine and agricultural products, unique culinary heritage, and so on [2], [3].

Because of globalization, minor traditions have gradually received increasingly more attention and have thus been recreated, reused, redefined, and redeveloped. Herbs and medicinal foods are also used in the creation of a diverse range of delicacies. Furthermore, with the rising of humanistic consciousness, local awareness, and value of respecting multi-nationality, to construct a multi-value system has become the major trend of thought of modern culture and cultures of local minorities have attracted a great deal of social concern

Furthermore, Cultural and Creative Industries is one of most developmental ones, which will deeply influence the nation's economic development through its market integration, market distribution of creative products and services, and the market restructuring of human resources [4]. Therefore, cultural and creative industries are emerging industries that the government of Taiwan has endeavored to develop in recent years. In particular, the creativity living industry is a unique industry in Taiwan. The government of Taiwan is making the agitation of creating industry's intention progressively through joint efforts of assistance and family property of the policy person too [5]. Creativity ponders how to seek a new path for traditions and to protect them from disappearing from the world. A reinterpretation of traditions is the creativity and innovation of traditions [6]. Creativity living industry may bring the declining traditional aboriginal culture with vitality.

Given the numerous cultures in Taiwan, diets of aborigines have a profound relationship with the natural ecosystem. Aboriginal diets not only interact with nature, but also reflect the wisdom of aboriginal tribes and the abundance of culture in the mountainous areas of Taiwan. Traditionally, aborigines pick edible wild vegetables, which have been a crucial food source for them since ancient times. The Amis people live in the eastern area of Taiwan where natural resources are abundant, and they thus have access to abundant food sources in the rivers, forests, mountains, and the sea (including vegetables, fruits, peat moss, laver, and kelp) [7]. In the current society where localization is embraced and people advocate natural health, aboriginal dietary culture in which local and natural foods with simple seasoning are served and simple cooking methods are used have started to receive increasingly more attention. Diet is the important foundation in constructing traditional culture in aboriginal tribes. 
In the present study, the Matai'an tribe in Guangfu, Hualien County, Taiwan served as a research base. Social network analysis (SNA) was adopted to holistically investigate and comprehensively analyze Amis dietary culture of the Matai'an tribe. This study has two main purposes: (1) Amis dietary culture of the Matai'an tribe; learn the generation process and connotation of Amis dietary culture of the Matai'an tribe; (2) Matai'an tribe Amis dietary culture to explore Matai'an tribe and reproduce the actions of Amis dietary culture and the correlation between each action and (3) to construct the strategic model in which the Matai'an Tribe transformed Amis dietary culture into the creativity living industry.

\section{LITERATURE REVIEW}

\section{A. Amis Dietary Culture}

Based on various previous researches and literatures on Amis dietary culture, this paper works out its characteristics [8]:

Prefer aquatic foods: living near the sea, Amis people have been accustomed to fishing, which is rather prevailing among the tribes along the coasts. Various kinds of fish, shellfish, sea snails and sea plants are all the favorite foods of Amis.

Profound culture of potherb: Amis may take the root, stem, leave, sprout, flower and fruit of more than a hundred types of plants for food. Amis call themselves the plants-eating nation, which reflects their dietary habits of preferring edible wild herbs. Although they will plant some vegetables in the garden nearby or in the farm, Amis people prefer the potherbs more and believe it is more tasteful.

Simple but special cooking methods: Amis people like processing the sea foods simply by grilling or smoking. As they also know how to make salts, they often use sea salt for pickling or seasoning.

The importance of water and wine: Amis people are fond of soup and cold water. Thus potherbs, fish and shellfish can all be used for simmering and boiling rather than frying, stir-frying and deep-frying which are often used by the Han people.

The food sources can be divided into self-produced, such as farming and breeding, and non-self-produced like picking, fishing, trading and presenting as gifts. With agriculture-centered (dry farmland and shifting cultivation), Amis dietary culture is closely connected with its geographical environment, featured by self-sufficiency.

Facing the trends of health-oriented consumption in now society, Amis dietary culture has become the diet style favored by people who pursue the healthy and natural diet. A culturally-based product may have strong potential - the interrelationship of culture/nature in traditional life ways and in the associated product features [9]. It is worthy discussing that how to make modern people accept Amis dietary culture and how to integrate the tradition and innovation to create a media that inheriting aboriginal culture. Creativity actually is to change the existing elements into new products by new combination or transformation. Creativity living culture may be the opportunity to rebuild the traditional industry of aboriginal tribes.

\section{B. Creativity Living Industry}

In 2002, the Taiwanese government proposed the "Challenge 2008 - National Development Plan," and admitted the creativity living industry into the "Cultural and Creative Industries Development Plan" as one of the categories for the cultural and creative industries. The creativity living industry is a category uniquely created based on the economic situation in Taiwan and practices used in other countries. Unlike other industries that target artists, designers, and cultural workers, the creativity living industry primarily targets traditional industries and is a part of the creative industries [10].

Business operations in the creativity living industry are focused on developing effective business strategies and interactive commodities along the dimensions of product, promotion, space, and service. These four major items must be interconnected to form a niche for and key characteristics of business management [11]. Currently, which types of businesses are entailed in the creativity living industry is not clearly defined; all businesses related to daily life activities and in possession of unique core knowledge, experiences, and aesthetic designs can be included in the creativity living industry. The creativity living industry of the intention is in the cultural intention industries put forward in recent years of Taiwan, act the traditional special role whose industry made the transition, combine and experience and design and create the new industry type attitude with style aesthetic feeling [6].

Food is a type of product that depicts local and cultural characteristics and local identification. It provides a special dietary experience for tourists. Indeed, cuisine is an attraction that is available year round at any time of the day and does not depend on weather conditions. Tourists often choose special destinations in order to taste specific traditional dishes typical of the region. Despite the fact that food can be used as a major travel motivation, there is a lack of scientific research into this subject [12]. This study explored the concept of diet and investigated how dietary culture can be transformed into the creativity living industry.

\section{Food Tourism}

Dietary culture represents a lifestyle of a group of people, and it includes previous and current cultural heritage and integrates physical and spiritual concepts [13]. Diet can reflect the local characteristics of an area and help people understand certain social and cultural implications. During the modernization of society, food has become an element of social and cultural functioning, reflecting specific social and cultural meanings. The dietary cultures of various countries effectively characterize the national cultures of countries [14]. Additionally, local dietary resources have other values and functions such as serving as a carrier of local dietary cultural heritage to embody local traditional culture, and as an option to develop local tourism resources and the local economy [15]. Local foods reflect the unique foods, animals, and plant resources of an area, as well as local climates. In a cultural poetic context featuring local colors, delicacies are a crucial part of the cultural landscape because they highlight the individuality of local cultures. Because cuisines have 
naturally developed over the years at the destination along with the local culture, history, and the area's natural resources, local and traditional foods are directly authentic to an area and the people [16].

Thus, tourism destinations can create a strong tourism image by exploiting unique culinary features and cultural assets [17]. Hall and Sharples [18] divided food tourism into three major categories according to the level of interest and the number of tourists. The first category, gourmet tourism (or gastronomic/cuisine tourism), has the most highly interested and committed food tourists. The second category, culinary tourism, has a moderate number of interested tourists. Culinary tourists appreciate food as a part of the essential experience but the emphasis is not on food. Culinary tourists are those who eat out in local, rustic, traditional, but also reasonably priced restaurants and place value on good quality and quantity. The third category, food tourism, is rural/urban tourism (or travel and tourism), which characterizes a clear majority of the tourists. These food tourists have low (or no) interest in any kind of food activities and consider eating as trying something different or as a plain necessity. Therefore, food tourism is not only exploration and adventure but also a cultural encounter because food tourists look for new restaurants, local tastes, and unique food experiences. Another advantage associated with this phenomenon is that it is not seasonal and can ultimately contribute to reactivating the local economy.

\section{MethodOLOGY}

\section{A. Data Collection}

On the basis of related studies and information, historical data were collected from relevant books, research reports, statistical data, and newspapers to explore the origins of Amis dietary culture (including natural and geographic conditions, production and living conditions, and social and cultural factors).

Field study and in-depth interviews with tribal elders, restaurant owners, and people who have hosted dietary cultural activities were conducted to elucidate the development of Amis dietary culture, thereby bridging the research gaps in previous studies.

Naturalistic observation was undertaken, in which research targets were observed in natural conditions without disturbing their behavior and observations were recorded in writing. Amis dietary culture was observed in dimensions of ecology, culture, and industry.

\section{B. Building a Social Network Relationship}

Social network refers to a specific tie and relationship established among individual nodes of a group in a certain manner. Function and authority is distributed across the nodes and linkages, such that decision-making and implementation are conducted through informal and temporary coalitions of actors and resources. SNA is a tool for examining network relationships. After identifying which actors are nodes, network data are collected through questionnaires, interviews, and observations and then input into an analysis software package to calculate various network indicators and depict network graphs representing various types of relationship.

The connection framework and interaction model among network members can be verified through SNA. Therefore, group phenomena can be explained using the concept of social networking [19]. In this study, University of California of Irvine Network (UCINET) 6.0 was used to explore individual actions within an overall structure. According to social network theory and an analysis of network centrality, critical actions in the network were identified to understand the role of various action factors in building an interactive network of transforming the Amis dietary culture into the creativity living industry.

\section{ANALYSIS AND RESULT}

\section{A. Coding and Analysis of the Interview Data}

A (providing traditional meals): The primitive cooking methods of the Amis people were adopted for tourists to experience tasting traditional cuisine (e.g., salted and grilled fish and stone hotpot).

B (developing creative dishes): Creative cooking methods were employed to prepare and promote exotic local foods that tourists would not normally accept (e.g., solanum coagulans, kakorot, okra, pigeon peas, and snails).

$\mathrm{C}$ (researching and developing special agricultural products): Through cooperation with the Industrial Development Bureau of the Ministry of Economic Affairs, local crops (e.g., purple rice, pigeon pea, kakorot, roselle, and rice) were incorporated into the design of souvenirs.

$\mathrm{D}$ (providing introductions and tours): Through ecological tours, bicycle tours, and interpretive illustrations attraction spots, tourists can learn about the natural ecology and cultural history of the Matai'an Wetland.

E (engaging visitors in actual operations): The traditional fishing method (Palakau) and cutlery-making method (e.g., betel leaf tableware, stone-hotpot cooking method, and mochi pounding) of the Amis people were demonstrated.

$\mathrm{F}$ (offering performances and demonstrations by local residents): Local residents demonstrated the traditional fishing (fish and shrimps) and cooking methods of the Amis people.

$\mathrm{G}$ (contract farming and purchasing and cultivating plants and raising animals for personal consumption): Business operators purchased foods from or entered contracts with specific farmers to ensure the origin of food ingredients (organic).

$\mathrm{H}$ (purchasing): Business operators purchased foods from markets or farms, and occasionally obtained free food from relatives or friends.

I (cultivating plants and raising animals for personal consumption): The ingredients for preparing indigenous dishes (Amis dishes) were cultivated in fields or yards. Accordingly, the freshness of foods can be ensured, and rare wild vegetables could be reproduced to ensure abundance of local specialty foods (water sprite).

$\mathrm{J}$ (providing mutual support among local residents): Local residents were employed to work part-time or full-time in restaurants and parks or to work as tour guides or performers.

$\mathrm{K}$ (attracting tourists from outside the community): Travel 
agents, government departments, and schools were consulted about itineraries to attract more tourists, generate additional income sources, and promote cultural and ecological education.

L (preserving the original features of Matai'an): The appearance of the local ecological environment was preserved as much as possible. For example, fences, boardwalks, and signs were used to minimize anthropogenic influences on the environment.

M (promoting indigenous Amis cultural styles): Culture and history workshops decorated with tools, clothing, totems, and craft works were established to recreate the atmosphere of the Amis tribe.

\section{B. Construct a Network Relationship Using SNA}

With Social Network Analysis (SNA), it analyzes the centrality intensity of all actions in dimensions like Ecological conservation, Cultural inheritance, Industry development when dietary culture is transferred into product, promotion, service and space. The higher intensity shows higher importance.

TABLE I: THE DIMENSION OF PRODU

\begin{tabular}{|c|c|c|c|}
\hline & $\begin{array}{l}\text { Ecological } \\
\text { conservation }\end{array}$ & $\begin{array}{l}\text { Cultural } \\
\text { inheritance }\end{array}$ & Industry development \\
\hline & NrmDegree / Share & NrmDegree / Share & NrmDegree / Share \\
\hline $\mathrm{A}$ & $75.000 \quad 0.098$ & $58.333 \quad 0.135$ & $91.667 \quad 0.141$ \\
\hline B & $75.000 \quad 0.098$ & $41.667 \quad 0.096$ & $66.667 \quad 0.103$ \\
\hline $\mathrm{C}$ & $75.000 \quad 0.098$ & $\begin{array}{ll}41.667 & 0.096\end{array}$ & $66.667 \quad 0.103$ \\
\hline $\mathrm{D}$ & $83.333 \quad 0.109$ & $41.667 \quad 0.096$ & $33.333 \quad 0.051$ \\
\hline $\mathrm{E}$ & $91.667 \quad 0.120$ & $25.000 \quad 0.058$ & $25.000 \quad 0.038$ \\
\hline $\mathrm{F}$ & $91.667 \quad 0.120$ & $25.000 \quad 0.058$ & $25.000 \quad 0.038$ \\
\hline $\mathrm{G}$ & $16.667 \quad 0.022$ & $\begin{array}{ll}8.333 & 0.019\end{array}$ & $50.000 \quad 0.077$ \\
\hline $\mathrm{H}$ & $25.000 \quad 0.033$ & $\begin{array}{ll}16.667 & 0.038\end{array}$ & $41.667 \quad 0.064$ \\
\hline I & $58.333 \quad 0.076$ & $75.000 \quad 0.173$ & $66.667 \quad 0.103$ \\
\hline $\mathrm{J}$ & $58.333 \quad 0.076$ & $\begin{array}{ll}8.333 & 0.019\end{array}$ & $41.667 \quad 0.064$ \\
\hline $\mathrm{K}$ & $50.000 \quad 0.065$ & $0.000 \quad 0.000$ & $0.000 \quad 0.000$ \\
\hline $\mathrm{L}$ & $66.667 \quad 0.087$ & 8.3330 .019 & $66.667 \quad 0.103$ \\
\hline M & $0.000 / 0.000$ & $83.333 / 0.192$ & $75.000 / 0.115$ \\
\hline
\end{tabular}

TABLE II: THE DIMENSION OF PROMOTION

\begin{tabular}{|c|c|c|c|c|c|c|}
\hline \multicolumn{3}{|c|}{$\begin{array}{l}\text { Ecological } \\
\text { conservation }\end{array}$} & \multicolumn{2}{|c|}{$\begin{array}{l}\text { Cultural } \\
\text { inheritance }\end{array}$} & \multicolumn{2}{|c|}{$\begin{array}{l}\text { Industry } \\
\text { development }\end{array}$} \\
\hline & NrmDegre & e / Share & NrmDegr & ee / Share & NrmDegre & e / Share \\
\hline $\mathrm{A}$ & 75.000 & 0.096 & 83.333 & 0.106 & 91.667 & 0.089 \\
\hline B & 75.000 & 0.096 & 66.667 & 0.085 & 91.667 & 0.089 \\
\hline $\mathrm{C}$ & 75.000 & 0.096 & 58.333 & 0.074 & 91.667 & 0.089 \\
\hline $\mathrm{D}$ & 83.333 & 0.106 & 83.333 & 0.106 & 100.000 & 0.097 \\
\hline $\mathrm{E}$ & 91.667 & 0.117 & 83.333 & 0.106 & 91.667 & 0.089 \\
\hline $\mathrm{F}$ & 91.667 & 0.117 & 83.333 & 0.106 & 100.000 & 0.097 \\
\hline $\mathrm{G}$ & 16.667 & 0.021 & 0.000 & 0.000 & 25.000 & 0.024 \\
\hline $\mathrm{H}$ & 25.000 & 0.032 & 58.333 & 0.074 & 66.667 & 0.065 \\
\hline I & 58.333 & 0.074 & 66.667 & 0.085 & 83.333 & 0.081 \\
\hline $\mathrm{J}$ & 58.333 & 0.074 & 58.333 & 0.074 & 91.667 & 0.089 \\
\hline $\mathrm{K}$ & 50.000 & 0.064 & 50.000 & 0.064 & 50.000 & 0.048 \\
\hline $\mathrm{L}$ & 75.000 & 0.096 & 8.333 & 0.011 & 75.000 & 0.073 \\
\hline M & 8.333 & 0.011 & 83.333 & 0.106 & 75.000 & 0.073 \\
\hline
\end{tabular}

According to the social network, the Matai'an tribe presented Amis dietary culture in various forms and practiced it in various ways. In the product dimension, promoting indigenous Amis cultural style was the most crucial for cultural inheritance; providing traditional meals was the most crucial for industry development. In the promotion dimension, actions of promotion and education category were equally crucial for cultural inheritance and industry development. Besides, in the product and promotion dimensions, "engaging visitors in actual operations and offering performances" and "demonstrations by local residents" were equally crucial for ecological conservation. In the service dimension, providing mutual support among local residents was equally crucial for ecological conservation, cultural inheritance and industry development. In the space dimension, actions of spatial development were equally crucial for ecological conservation, cultural inheritance and industry development. These data suggest that Matai'an tribe used space as a medium for promoting traditional culture, which then became the basis for the creativity living industry, as well as for marketing local delicacies, craft works, agricultural products, cultural landscape, and in-depth tourism.

TABLE III: THE DIMENSION OF SEVERICE

\begin{tabular}{|c|c|c|c|c|}
\hline & \multicolumn{2}{|c|}{$\begin{array}{l}\text { Ecological } \\
\text { conservation } \\
\end{array}$} & $\begin{array}{l}\text { Cultural } \\
\text { inheritance } \\
\end{array}$ & $\begin{array}{l}\text { Industry } \\
\text { development }\end{array}$ \\
\hline & NrmDegre & / Share & NrmDegree / Share & NrmDegree / Share \\
\hline $\mathrm{A}$ & 75.000 & 0.102 & $\begin{array}{ll}58.333 & 0.140\end{array}$ & $\begin{array}{ll}66.667 & 0.091\end{array}$ \\
\hline B & 66.667 & 0.091 & $33.333 \quad 0.080$ & $50.000 \quad 0.068$ \\
\hline $\mathrm{C}$ & 66.667 & 0.091 & $0.000 \quad 0.000$ & $41.667 \quad 0.057$ \\
\hline $\mathrm{D}$ & 66.667 & 0.091 & $50.000 \quad 0.120$ & $75.000 \quad 0.102$ \\
\hline $\mathrm{E}$ & 50.000 & 0.068 & $50.000 \quad 0.120$ & $58.333 \quad 0.080$ \\
\hline $\mathrm{F}$ & 50.000 & 0.068 & $50.000 \quad 0.120$ & $58.333 \quad 0.080$ \\
\hline G & 41.667 & 0.057 & $0.000 \quad 0.000$ & $8.333 \quad 0.011$ \\
\hline $\mathrm{H}$ & 41.667 & 0.057 & $0.000 \quad 0.000$ & $16.667 \quad 0.023$ \\
\hline I & 41.667 & 0.057 & $0.000 \quad 0.000$ & $25.000 \quad 0.034$ \\
\hline $\mathrm{J}$ & 91.667 & 0.125 & $58.333 \quad 0.140$ & $91.667 \quad 0.125$ \\
\hline $\mathrm{K}$ & 58.333 & 0.080 & $58.333 \quad 0.140$ & $75.000 \quad 0.102$ \\
\hline $\mathrm{L}$ & 83.333 & 0.114 & $0.000 \quad 0.000$ & $83.333 \quad 0.114$ \\
\hline M & 0.000 & 0.000 & $58.333 \quad 0.140$ & $83.333 \quad 0.114$ \\
\hline
\end{tabular}

TABLE IV: THE DIMENSION OF SPACE

\begin{tabular}{lrlrlrl}
\hline & \multicolumn{2}{c}{$\begin{array}{l}\text { Ecological } \\
\text { conservation }\end{array}$} & \multicolumn{3}{c}{$\begin{array}{l}\text { Cultural } \\
\text { inheritance }\end{array}$} & \multicolumn{2}{c}{ Industry development } \\
\hline \multicolumn{3}{c}{ NrmDegree / Share } & \multicolumn{2}{c}{ NrmDegree / Share } & NrmDegree / Share \\
\hline A & 41.667 & 0.147 & 41.667 & 0.147 & 50.000 & 0.125 \\
B & 16.667 & 0.059 & 16.667 & 0.059 & 25.000 & 0.063 \\
C & 0.000 & 0.000 & 16.667 & 0.059 & 25.000 & 0.063 \\
D & 41.667 & 0.147 & 33.333 & 0.118 & 41.667 & 0.104 \\
E & 33.333 & 0.118 & 41.667 & 0.147 & 41.667 & 0.104 \\
F & 33.333 & 0.118 & 33.333 & 0.118 & 41.667 & 0.104 \\
G & 0.000 & 0.000 & 0.000 & 0.000 & 0.000 & 0.000 \\
H & 8.333 & 0.029 & 0.000 & 0.000 & 0.000 & 0.000 \\
I & 33.333 & 0.118 & 33.333 & 0.118 & 41.667 & 0.104 \\
J & 0.000 & 0.000 & 0.000 & 0.000 & 0.000 & 0.000 \\
K & 0.000 & 0.000 & 0.000 & 0.000 & 0.000 & 0.000 \\
L & 66.667 & 0.235 & 8.333 & 0.029 & 66.667 & 0.167 \\
M & 8.333 & 0.029 & 66.667 & 0.235 & 66.667 & 0.167 \\
\hline \hline
\end{tabular}

In addition, according to the analytical results for the product and space dimensions, through managing traditional Amis cuisines, providing ingredients required for creative Amis delicacies, and constructing a catering environment, the geographical landscape of Matai'an Wetland and biological habitats are preserved and unique edible plants are reproduced to protect the ecology and ensure biological 
diversity. Amis dietary culture promotes the concept of coexistence with the natural environment, becoming a form of Matai'an cultural heritage.

Finally, according to the analytical results for the product, promotion and service dimensions, when local indigenous peoples are employed and trained as tour guides, they gain insight into the precious experiences of tribal elders and the values of traditional culture and ecological wisdom, and subsequently identify with and exhibit a sense of belonging to their culture.

\section{CONCLUSION}

This research found that dietary culture offers an alternative means of local and regional development, with the potential to strengthen identity, enhance appreciation of the environment, to encourage the regeneration of local heritage and the economy. The local food consumption plays an important role not only on enriching the recreation experiences, but also providing an opportunity to extend local culture features. Local dietary resources are used to satisfy the dietary needs of local people and to develop local dietary cultures. Tourist consumption of local foods creates a market opportunity that can encourage the development of sustainable agriculture, help conserve traditional farming landscapes and assist the local economy. Ecotourism also benefits the promotion of local employment and brings natural resources into aboriginal daily life to preserve local characteristics. Moreover, Amis dietary culture attracts tourists and stimulates local economic growth. The local economy and industries can be diversified to achieve the prosperity of an ecological environment, social and cultural lifestyles, and a production-based economy. This research found that dietary culture offers an alternative means of local and regional development, with the potential to strengthen identity, enhance appreciation of the environment, to encourage the regeneration of local heritage and the economy.

Aboriginal creativity living industry is composed of many delicate cultural elements full of local features, including diet, festivals, handicraft, performing arts, natural environment and agricultural products. By deconstructing and reutilizing with a brand new method, the existing cultural elements are appropriately planned into activities such as recreation and sightseeing, ecological guide, cultural workshop and life experiencing. By transferring the primary industries in the tribes into creativity living industries, it can bring the tribe a completely new scene, which can trigger and extend the memories in existing cultural elements again and create endless space for the development of aboriginal culture. Moreover, for the aboriginal tribes, under the circumstance of ecological tourism, it is an important issue concerning the sustainable development of aboriginal creativity living culture industry that how to connect itself with modern sci-tech cultivation and popularize the national features as well as inherit the cultural connotation.

Aboriginal tourism is increasingly seen as a strategy for economic diversification by many Aboriginal communities. Existing research indicates that the traditional economic structure and cultural context of aboriginal tribes may develop a new cultural pattern after tourism development is drawn into aboriginal living territory. Especially the introduction of ecotourism and tourist experience activities can positively support the conservation of local characteristics and contribute to ecological conservation. Overall, production and consumption processes in the creativity living industry increased job opportunities and local incomes. The sustainable development of an indigenous tribal industry can be achieved by focusing on nature-based ecotourism, the creativity living industry based concepts, unique tribal cultural resources and natural landscapes, leisure activities aimed at conserving nature and achieving sustainable development, conventional industrial technologies, the creation of a knowledge economy, and integration of tradition and innovation.

\section{REFERENCES}

[1] S. C. Lai, "The reconstruction of ethnic food culture under the dynamics of modern consumer culture: A case study of the transformation of taiwan "Hakka Cuisine" into a form of leisure consumption," Journal of State and Society, vol. 1, pp. 167-212, 2006.

[2] J. Kivela and J. Crotts, "Gastronomy tourism: A meaningful travel market segment," Journal of Culinary Science \& Technology, vol. 4, no. (2/3), pp. 39-55, 2005.

[3] H. F. Tang, C. Wu, and C. Y. Chang, "The motivation and experiences of local food consumption in rural tourism," Leisure and Recreation Research, vol. 1, no. 2, pp. 113-136, 2007.

[4] K. T. Lam, "Remarks on economic sustainable development for cultural and creative industries," Journal of Cultural and Creative Industries Research, vol. 2, no. 2, pp. 197-210, 2012.

[5] M. L. Lai, S. H. Hwang, and C. F. Lee, "The life industry of the intention promotes and operates studying in Taiwan," The Journal of Design Research, vol. 5, pp. 158-166, 2005.

[6] Y, F. Pan, "Explore the actions of creative development of Taiwan's aboriginal culture - Visit the United States, Canadian aboriginal culture reflection," Taiwan indigenous studies review, vol. 1, pp. 103-124, 2007.

[7] Y. W. Lin, and L. L. Wang, "A preliminary study of the fishing culture of amis in fataan tribe," Hwa Kang Journal of Agriculture, vol. 22, pp 57-69, 2008

[8] Y. Z. Kuo, "Amis traditional agricultural knowledge," Taiwan indigenous studies review, vol. 5, pp. 99-124, 2009.

[9] D. Kutzner and P. A. Wright, "An investigation into key market segments for Aboriginal tourism in northern British Columbia, Canada," Journal of Vacation Marketing, vol. 16, no. 2, pp. 97-110, 2010.

[10] F. J. Lin and Y. L Lin, "The study of leisure farm competitiveness in Yilan area under the creative life industries," Sun Yat-Sen Management Review, vol. 20, no. 4, pp. 1143-1176, 2012.

[11] W. H. Chang, "The designed concepts of creativity living industry," Science Development, vol. 453, pp. 20-29, 2010.

[12] C. L. Beer, M. C. Ottenbacher, and R. J. Harrington, "Food tourism implementation in the black forest destination," Journal of Culinary Science \& Technology, vol. 10, pp. 106-128, 2012.

[13] C. C. Teng, "The transformation of the hakka dietary culture in Hsinchu," Journal of Hospitality and Home Economics, vol. 6, no. 4, pp. 353-377, 2009

[14] H. C. Lin, "The dietary culture restructuring of Lanyu tao people-a study of cultural ecology," Journal of Hospitality and Home Economics, vol. 6, no. 1, pp. 1-12, 2009.

[15] M. K. Ju, "Local cuisine culture resource and its development research," Culinary Science Journal of Yangzhou University, vol. 27, no. 4, pp. 14-19, 2010.

[16] R. Sims, "Food, place and authenticity: Local food and the sustainable tourism experience," Journal of Sustainable Tourism, vol. 17, no. 3, pp. 321-336, 2009

[17] C. M. Hall and R. Mitchell, "Gastronomic tourism: Comparing food and wine tourism experiences," in Niche tourism: Contemporary issues, trends and cases, Oxford, UK: Butterworth-Heinemann, 2005, pp. 73-78. 
[18] C. M. Hall and L. Sharples, "Food tourism around the world-Development, management and markets," The consumption of Experiences or the Experience of Consumption? An Introduction to the Tourism of Taste, Oxford, UK: Butterworth-Heinemann, 2003, pp. $1-25$.

[19] C. Y. Huang, W. L. Chang, H. L. Lee, and M. H. Lai, "Exploring the industry innovation diffusion through social network analysis in local rice industry," Soochow Journal of Economics and Business, vol. 73, pp. 67-108, 2011.

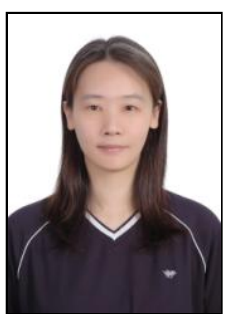

Yi-Su Chen was born in Kaohsiung, Taiwan on May 1, 1982. She was graduated from Feng Chia University, with the master's program of Landscape \& Recreation, Taichung, Taiwan in 2008. She is currently a sixth year $\mathrm{PhD}$ student at Feng Chia University, Taichung, Taiwan in Civil and hydraulic engineering with resource management as major field of study.
She had worked as a marcom specialist at a Chiayi Farm Ecological Resort Country in Chiayi, Taiwan and as an executive secretary at Chrshang Township Administration in Taitung, Taiwan during 2007-2011. Besides, she has been actively teaching hotel and restaurant management at Feng Chia University, Taichung, Taiwan since 2013.

She has published several papers which about community development and cultural industries. Her research interests are including rural development and SNA (social network analysis). 